\title{
Recent Advances Of Mucosal Capnometry And The Perspectives Of Gastrointestinal Monitoring In The Critically Ill. A Pilot Study
}

\author{
Péter Palágyi ${ }^{*}$, Sándor Barna², Péter Csábi³ ${ }^{3}$ Péter Lorencz ${ }^{1}$, Ildikó László ${ }^{1}$, Zsolt Molnár ${ }^{1}$ \\ 1 Department of Anaesthesiology and Intensive Therapy, University of Szeged, Hungary \\ 2 Department of Anaesthesiology and Intensive Therapy, Bács-Kiskun County Hospital, Teaching Hospital of the \\ University of Szeged, Hungary \\ ${ }^{3}$ Department of Anaesthesia and Intensive Care, Wexham Park Hospital, United Kingdom
}

\begin{abstract}
Mucosal capnometry involves the monitoring of partial pressure of carbon dioxide (PCO2) in mucous membranes. Different techniques have been developed and applied for this purpose, including sublingual or buccal sensors, or special gastrointestinal tonometric devices. The primary use of these procedures is to detect compensated shock in critically ill patients or patients undergoing major surgery. Compensatory mechanisms, in the early phases of shock, lead to the redistribution of blood flow towards the vital organs, within ostensibly typical macro-haemodynamic parameters. Unfortunately, this may result in microcirculatory disturbances, which can play a pivotal role in the development of organ failure. In such circumstances mucosal capnometry monitoring, at different gastrointestinal sites, can provide a sensitive method for the early diagnosis of shock. The special PCO2 monitoring methods assess the severity of ischaemia and help to define the necessary therapeutic interventions and testing of these monitors have justified their prognostic value. Gastrointestinal mucosal capnometry monitoring also helps in determining the severity of ischaemia and is a useful adjunctive in the diagnosis of occlusive splanchnic arterial diseases. The supplementary functional information increases the diagnostic accuracy of radiological techniques, assists in creating individualized treatment plans, and helps in follow-up the results of interventions. The results of a pilot study focusing on the interrelation of splanchnic perfusion and gastrointestinal function are given and discussed concerning recent advances in mucosal capnometry.
\end{abstract}

Keywords: capnometry, carbon-dioxide gap, perfusion, oxygenation, enteral feeding, motility

Received: 21 September 2015 / Accepted: 05 December 2015

\section{INTRODUCTION}

The clinical significance of monitoring the gastrointestinal circulation is based on several factors. It is well recognized that in the early phase of shock, compensatory mechanisms lead to the redistribution of blood flow from the gut to other organs, resulting in the normalization of macrohemodynamic parameters. Consequently, in spite of normal values of global oxygen delivery, gastrointestinal hypoperfusion may occur and remains undiagnosed by conventional monitoring tools. This phenomenon explains the sensitivity of mucosal capnometry for the diagnosis of compensated shock. Unfortunately, during this redistribution phase, increased intestinal permeability and microcirculatory insufficiency can result in tissue hypoxia, which may eventually lead to toxin translocation from the gut into the circulation, causing organ dysfunction and the development of multiple organ failure $[1,2]$. In haemorrhagic shock, buccal $\mathrm{PCO}_{2}$ monitoring proved to be useful in both the diagnosis and the quantification of bleeding [3-5]. In animal experiments, buccal $\mathrm{PCO}_{2}$ values were found to be sensitive to hypoperfusion, and also showed a strong correlation with outcomes,

\footnotetext{
Correspondence to: Péter Palágyi MD., University of Szeged, Department of Anaesthesiology and Intensive Therapy, 6. Semmelweis St, 6725 Szeged, Hungary.

E-mail: peter@med.u-szeged.hu

Sándor Barna: Department of Anaesthesiology and Intensive Therapy, Bács-Kiskun County Hospital, Teaching Hospital of the University of Szeged, 6000 Kecskemét, Nyíri út 38 , Hungary

Péter Csábi: Department of Anaesthesia and Intensive Care, Wexham Park Hospital, United Kingdom, Wexham, Slough, Berkshire, SL2 4HL

Péter Lorencz: University of Szeged, Department of Anaesthesiology and Intensive Therapy, 6. Semmelweis St, 6725 Szeged, Hungary.

Ildikó László: University of Szeged, Department of Anaesthesiology and Intensive Therapy, 6. Semmelweis St, 6725 Szeged, Hungary.

Zsolt Molnár: University of Szeged, Department of Anaesthesiology and Intensive Therapy, 6. Semmelweis St, 6725 Szeged, Hungary.
} 
compared to traditional vital signs or blood gas parameters. Similar findings have been reported, using sublingual capnometric monitoring during bleeding, in both human and animal studies [6,7]. The results of a haemorrhagic shock model in pigs, when complex hemodynamic and blood gas measurements were performed in addition to sublingual capnometry and orthogonal polarisation spectral imaging (OPS) during severe bleeding, were recently detailed [8]. The results suggest that, sublingual to arterial $\mathrm{PCO}_{2}$ gap values, correlated well with microcirculatory parameters gained by videomicroscopy, and the combination of capnometric monitoring with arterial and central venous blood gas parameters may improve the diagnostic accuracy of haemodynamically relevant haemorrhage or other types of hypoperfusion. The utility of mucosal $\mathrm{PCO}_{2}$ monitoring was also verified in septic shock in pigs when the early signs of circulatory insufficiency were detected by simultaneous intestinal mucosal capnometry monitoring and microcirculatory assessment using OPS, but not by conventional clinical parameters like arterial blood pressure, urinary output or lactate levels [9].

\section{Mucosal capnometry and respiratory monitoring}

In patients with stable haemodynamics and good peripheral circulation tissue $\mathrm{PCO}_{2}$ changes closely follow the arterial $\mathrm{PCO}_{2}$ alterations. The first application of a ballooned gastric tonometer in a pediatric population with respiratory paralysis was based on this principle [10]. As these patients did not suffer from circulatory failure, they only had a minor difference of 2-3 $\mathrm{mmHg}$ between their gastric and arterial $\mathrm{PCO}_{2}$. In such circumstances, sudden changes of the absolute value of gastric or other gastrointestinal mucosal $\mathrm{PCO}_{2}$ may indicate respiratory disturbances. This was the case of a nine-month infant, born with combined congenital cardiac abnormalities, in whom an abrupt increase in gastric $\mathrm{PCO}_{2}$ was detected during aggressive mechanical ventilation, and was followed by the diagnosis of a severe respiratory complication of tension pneumothorax [11]. In a validation study of a new sublingual capillary tonometer, performed in COPD patients, sublingual $\mathrm{PCO} 2$ values decreased in parallel with arterial blood PCO2 during hyperventilation [12]. These observations suggest that in patients without compromised circulation sublingual capnometry may indicate short term changes in arterial PCO2.

\section{Gastric tonometry in the diagnosis of splanchnic artery stenosis}

Acute gastrointestinal ischemia has a high incidence in shock, which condition is a common scenario in perioperative medicine and intensive care $[13,14]$. In most cases it is not related to significant anatomical stenoses of gastrointestinal tract vessels, but it is due to compensatory vasoconstriction. This condition is also named non-occlusive mesenteric ischemia (NOMI). The main goals of its therapy include the restoration of circulating blood volume and stabilization of haemodynamics. Splanchnic ischemia, however, may also be due to arteriosclerosis or external compression of the coeliac and mesenteric arteries. Various vague ischaemic symptoms may develop, which depend on the duration and the degree of blood flow reduction. Strong abdominal pain and "acute abdomen" is characteristic in acute splanchnic syndrome (ASS), while postprandial pain and weight loss are typical but non-specific symptoms in chronic splanchnic syndromes (CSS) [15]. Gastrointestinal tonometry has a role in the diagnosis of ongoing ischemia, as the association of hypoperfusion with increased $\mathrm{PCO}_{2}$ has been observed in ischaemic models and animal experiments [16-18]. While the diagnosis of an acute abdominal catastrophe is simple, recognizing chronic ischemia may be extremely difficult. Kolkman developed a diagnostic approach in which gastrointestinal tonometry played a pivotal role $[19,20]$. The sensitivity of gastric tonometry was increased by using a ten-minute bicycle exercise test or a test meal, and coined the term, gastric exercise tonometry (GET). These tests can provoke and detect mucosal ischaemia, and can be successfully used for the diagnosis of different occlusive arterial diseases [21]. Combined non-invasive screening with exercise tonometry and duplex ultrasonography showed excellent accuracy in detecting chronic gastrointestinal ischemia while the application of various imaging methods can give morphological diagnosis only. Besides, in this series of investigations, GET proved its practicability in the selection of patients who can most benefit from surgery or PTA/stent placement.

\section{The correlation between gastric mucosal perfusion and emptying in a pilot study}

Enteral feeding is undoubtedly superior to parenteral nutrition [22,23]. Effective enteral nutrition, however, requires functioning gastrointestinal tract, often missing in the critically ill patient [24]. The factors neces- 
sary for the maintenance of the physiological structure and mucosal perfusion (Figure 1), are often compromised due to circulatory disturbances in patients in an ICU. Although good peripheral circulation is unlikely when unstable haemodynamics exist, regional hypoperfusion may be present due to normal macro-hemodynamic and oxygenation parameters $[9,25,26]$. This fact underlines the potential importance of monitoring regional perfusion in this group of patients.

Mucosal capnometry is the monitoring of the partial pressure of carbon dioxide $\left(\mathrm{PCO}_{2}\right)$ in mucous membranes. Its history began with the invention of gastro tonometry [10], which method allowed the measurement of intraluminal $\mathrm{PCO}_{2}$ and the calculation of intramu$\operatorname{cosal~} \mathrm{pH}(\mathrm{pHi})$ in the gastric mucosa. The method was first used in the University of Szeged, Hungary for the adjustment of ventilators in poliomyelitic children with respiratory insufficiency [10]. As these patients were haemodynamically stable, the gastric carbon-dioxide levels closely followed systemic arterial carbon-dioxide values. This observation was confirmed in animal experiments and in human volunteers with normal perfusion, in whom the changes in alveolar ventilation and arterial $\mathrm{PCO}_{2}$ resulted in parallel changes of the tonometric variables [27-29]. The significance of gastric tonometry, in detecting the failure of regional perfusion, was recognized later, when substantial differences were found between gastric and arterial $\mathrm{PCO}_{2}$ in various clinical and experimental studies [30]. The magnitude of this difference, the so-called gastric-to-arterial $\mathrm{PCO}_{2}$ gap $\left(\mathrm{PgaCO}_{2}\right)$, corresponds with the severity of the disease and splanchnic perfusion failure and proved to be an important prognostic factor [31,32]. More than 3000 articles have been published on this topic, in the areas including intensive care, perioperative and transplantation medicine, traumatology, sepsis, and cardiology, yet gastric tonometry is still not used as much as would be expected. This might be due to pitfalls of $\mathrm{pHi}$ calculation, the interference of gastric acid and enteral feeding, and technical difficulties [16,33] which have lead to the gradual abandonment of tonometric monitors. Despite the development of gastric tonometry. [34], interest turned to the capnometric monitoring at other sites of the gastrointestinal mucosa. In the last decades, several investigators have reported a correlation between the $\mathrm{PCO}_{2}$ values of the oral and gastric mucosa in different pathological conditions $[35,36]$ and has resulted in the use of sublingual or buccal mucosal capnometry. These methods do not have the limitations of gastric tonometry and are increasingly used for the measurement of $\mathrm{PCO}_{2}$ in the mucosa, and the calculation of mucosal-to-arterial $\mathrm{PCO}_{2}$ gap [3,37]. Currently buccal or sublingual mucosal capnometry has wide range applications in medical research and a remarkable potential for patient monitoring.

The aim of the study is to present the results of a preliminary investigation concerning the relationship between gastric emptying and regional perfusion detected by gastric mucosal capnometry in critically ill patients.

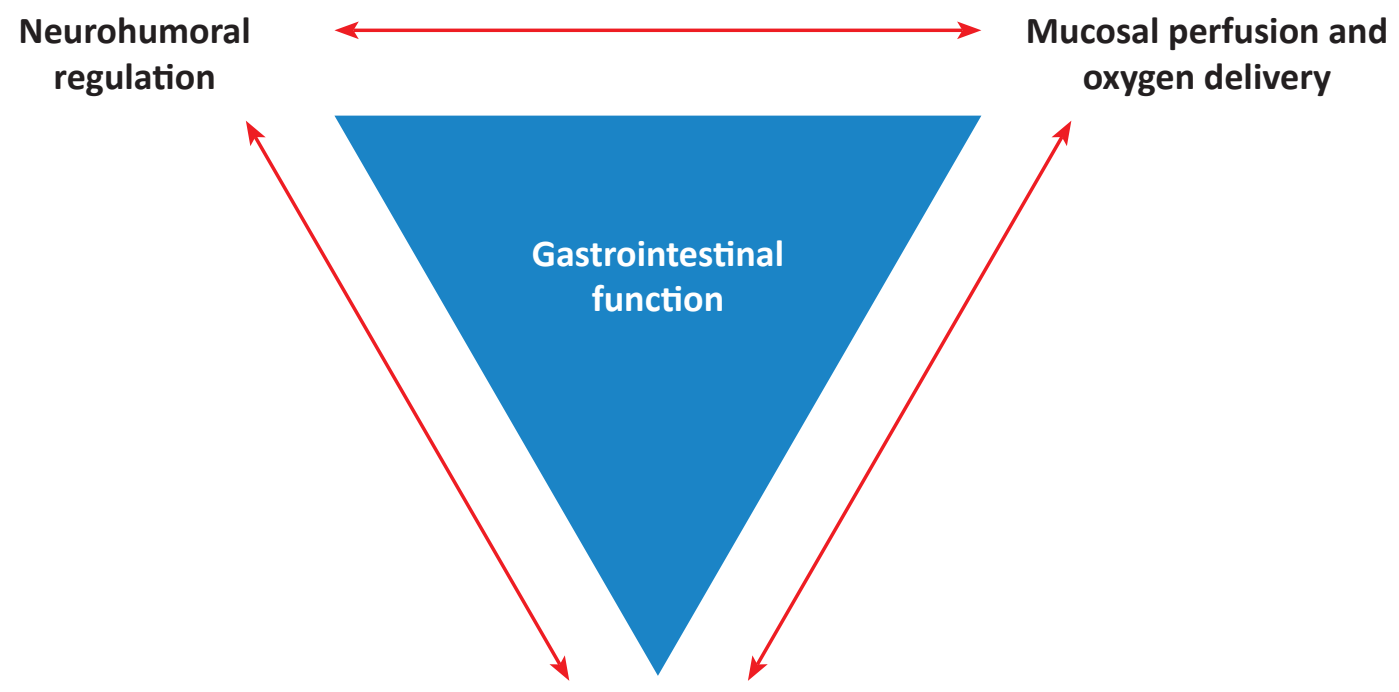

Intraluminal nutrients, prebiotics

Fig. 1. Factors contributing to the physiologic function of the gastrointestinal tract. (For explanation, see text.) 


\section{METHODS}

Critically ill, mechanically ventilated patients were included in our prospective observational study. The study was approved by the Regional Human Biomedical Research Ethics Committee of the University of Szeged. All patients were informed of the procedures and gave written concent.

A conventional nasogastric tube was introduced into the stomach to provide enteral feeding, and a silicon gastrotonometric device was inserted through the other nostril, for gastric mucosal $\mathrm{PCO}_{2}$ measurements. The features of this special probe have been described earlier [38]. The patients were given proton-pump inhibitors twice a day in order to reduce the interference of gastric acid. After early cardiopulmonary stabilization $1 \mathrm{kcal} / \mathrm{ml}$ standard enteral formula (Nutrison Standard, Nutricia) was started via the feeding tube. The caloric requirements were defined as $20-25 \mathrm{kcal} /$ $\mathrm{kg}$, for obese patients with a BMI $>30 \mathrm{~kg} / \mathrm{m} 2$. In case of delayed gastric emptying, with higher residual gastric volume (RGV), the algorithm depicted on Figure 2. was used for dose adjustments. Feeding was stopped two hours before tonometric measurements, to minimize the confounding effects of nutrition. At the end of these feeding pauses, overall arterial and central ve- nous blood-gas analysis and gastric tonometric measurements were performed twice a day (Figure 3). The main clinical end-points were the amount of RGV in eight-hour periods and the enteral caloric intake in the last 24 hours (actual energy=Ea) divided by the previously calculated optimal daily caloric intake (total energy $=\mathrm{Et}$ ). The $\mathrm{Ea} / \mathrm{Et}$ ratio reflected the daily status of enterally administered nutrients compared to total caloric needs. The occurrence of feeding intolerance and complications eg. aspiration, regurgitation, vomitus, bowel distention, and diarrhea were also recorded. Subgroups were created in a post hoc fashion according to the median $\mathrm{PgaCO}_{2}$ value and divided into "low" (LG) and "high" (HG) $\mathrm{PgaCO}_{2}$ groups.

The main outcome parameters were the differences in RGV and Ea/Et ratios. The numeric data in the text and values on the figures are given as median and 25th and $75^{\text {th }}$ percentiles.

The Bartlett test was used to verify if samples were from populations with equal variances and the Kolmogorov-Smirnov test used to determine normal distribution. Individual groups were compared by Mann-Whitney test. Data analysis was done using the statistical software package SigmaStat for Windows (Jandel Scientific, Erkrath, Germany). The level of statistical significance was set at $\alpha=0.05$.

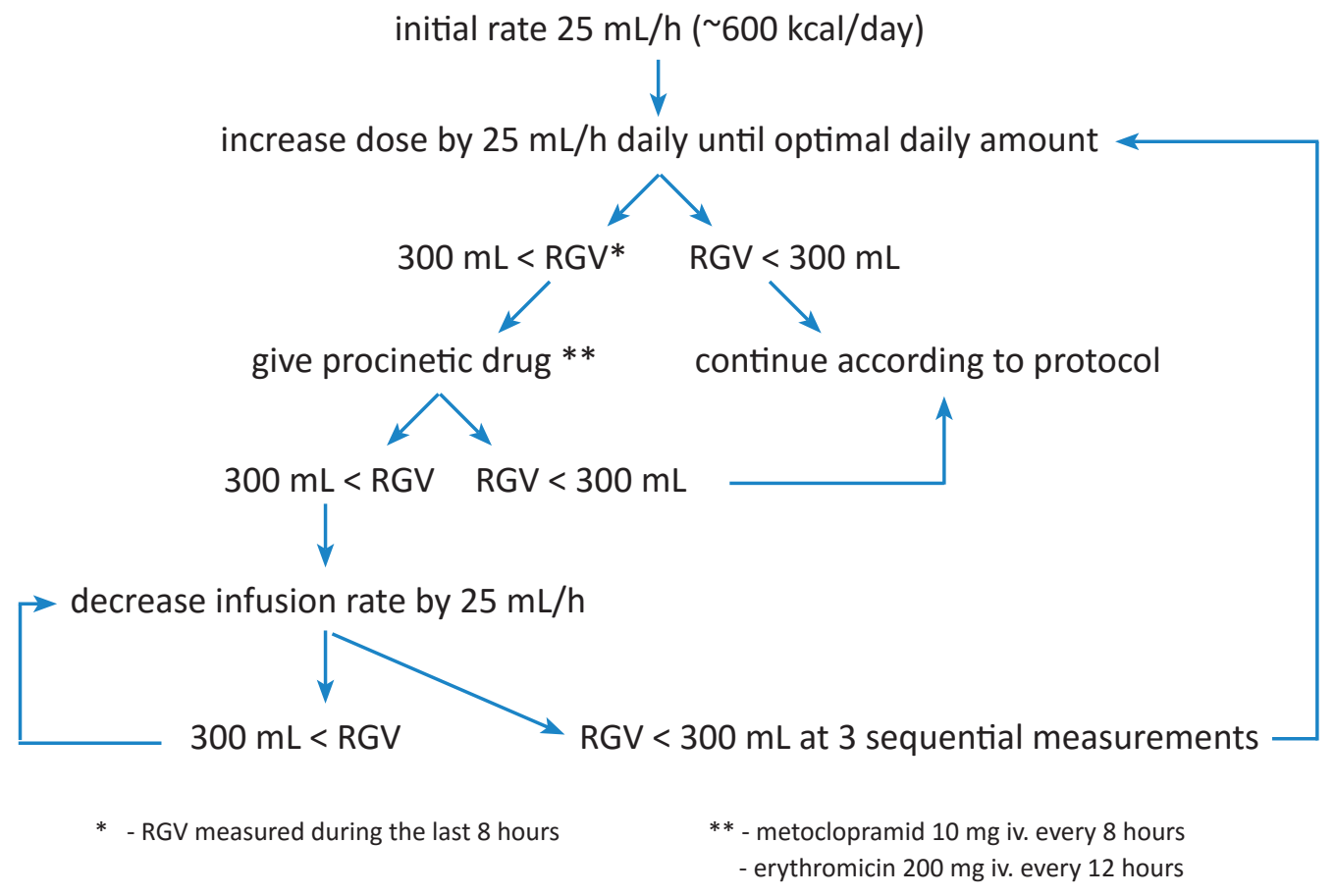

Fig. 2. Protocol for dose adjustments during early enteral feeding. (RGV, residual gastric volume. For further explanation see text.) 


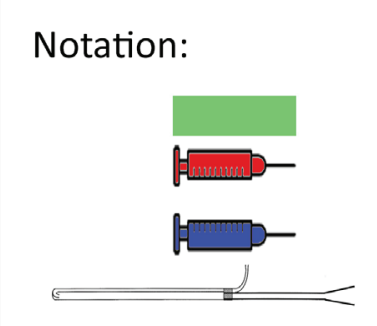

Continuous enteral nutrition

Arterial blood gas sampling

Venous blood gas sampling

Gastric tonometry sampling

Residual gastric volume measurement

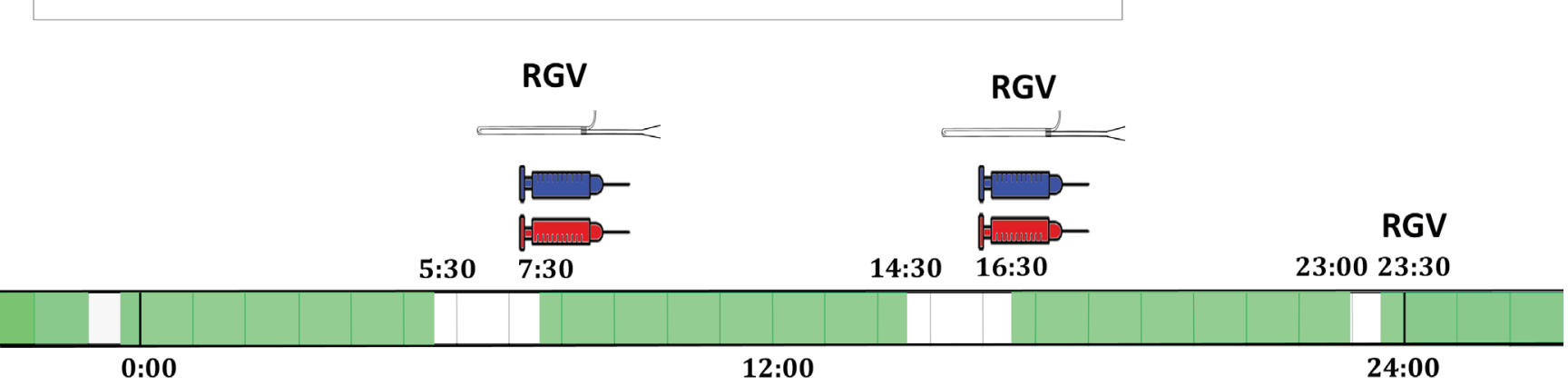

Fig. 3. Sampling protocol during early enteral nutrition. (For explanation see text.)

\section{RESULTS}

The data of eighty separate measurement points in eighty critically ill patients were analyzed. The clinical characteristics of the study population are summarized in Table 1 . The average APACHE II score of the whole sample was twenty-six points with a calculated mortality risk of about $55 \%$. In $50 \%$ of the patients, the average $\mathrm{PgaCO}_{2}$ was lower while in the other $50 \%$ higher than $29 \mathrm{mmHg}$. This was the median value to develop

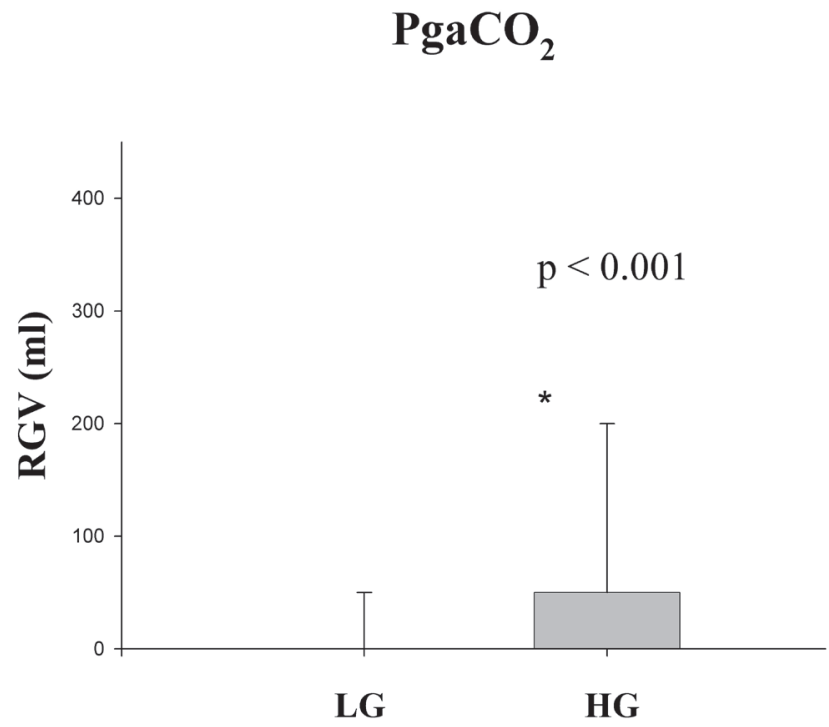

Fig. 4. Differences in the average residual gastric volume (RGV) between patients with low (LG) and high (HG) PgaCO $\mathbf{2}_{2}$ levels. (* $p<0.001$ Mann-Whitney Rank Sum test.) the two groups (LG and HG). The amount of RGV was found significantly lower in the LG as compared to the HG: 0 (0-50) compared to $50(30-200) \mathrm{ml}, \mathrm{p}<0.001$ (Figure 4). Differences in physiological parameters, such as central venous oxygen saturation $\left(\mathrm{ScvO}_{2}\right)$, serum lactate (seLac) and central venous-to-arterial $\mathrm{CO}_{2}$

Table 1. Clinical characteristics of the patients involved in the study

\begin{tabular}{lc} 
Age (years) & $\mathbf{7 4}$ (59-87) \\
\hline Gender (m/f) & $4 / 4$ \\
\hline APACHE II. score & 26 \\
\hline Mortality risk (\%) & 55 \\
\hline Mortality (\%) & 37 \\
Diagnosis (n) & 3 \\
\hline intracranial haemorrhage & 2 \\
\hline subarachnoid haemorrhage & 1 \\
\hline sepsis, MOF & 2 \\
\hline cardiogenic shock &
\end{tabular}

Table 2. Differences in physiological parameters. LG, "low" group; HG, "high" group; $\mathrm{PcvaCO}_{2}$, central venous-to-arterial $\mathrm{CO}_{2}$ gap; $\mathrm{ScvO}_{2}$, central venous oxygen saturation; seLac, serum lactate. Values are expressed as median and 75 th and 25 th percentiles.

\begin{tabular}{lcc} 
& LG & HG \\
$\mathrm{PcvaCO}_{2}(\mathrm{mmHg})$ & $6.0(4.6 .7 .0)$ & $7.0(5.0-8.0)$ \\
\hline $\mathrm{ScvO}_{2}(\%)$ & $80(77-82)$ & $75(68-81)$ \\
\hline $\mathrm{seLac}(\mathrm{mmol} / \mathrm{L})$ & $1.1(0.9-1.2)$ & $1.6(1.1-3.2)$ \\
\hline
\end{tabular}


gap $\left(\mathrm{PcvaCO}_{2}\right)$ levels are summarized in Table 2. There was no statistically significant difference in the rate and escalation of enteral feeding, and the $\mathrm{Ea} / \mathrm{Et}$ quotient was also found similar in the groups. Complications attributable to early enteral feeding were uncommon, short-term diarrhea stopped by feeding-pause were reported in two individuals and suspected regurgitation and aspiration in one case.

\section{DISCUSSION}

During critical illness, the provision of enteral feeding is crucially important. Unfortunately, gastrointestinal dysfunction, including dysmotility and malabsorption, may hinder nasogastric tube feeding. According to the literature, its aetiology is multicausal $[22,23,39,40]$, and concomitant complications may inhibit the application of a more physiologic way of providing nutrition. As the severity of the illness is associated with higher incidence of gastrointestinal complications and insufficient enteral calorie delivery, this vicious circle worsens the clinical outcome and delays recovery. Consequently, barriers to feeding are of great significance in high risk patients [40]. Normal splanchnic blood flow is a key factor in the maintenance of the healthy bowel system. The relationship between regional and global blood flow and gastric emptying was investigated in this pilot study. Mucosal capnometry devices allowed the indirect monitoring of gastrointestinal regional perfusion $[38,41]$, while from simultaneously drawn arterial and central venous blood gas parameters assessed patients' macro-hemodynamic and oxygenation status. The different blood gas values have particular implications for systemic oxygen balance: $\mathrm{ScvO}_{2}$ refers to the proportion of global oxygen delivery and consumption, Pc$\mathrm{vaCO}_{2}$ describes the relationship of cardiac output to global metabolism and microvascular blood flow, and seLac is a well-known parameter of inadequate tissue perfusion related anaerobic metabolism [42]. Although the measurement of RGV is a rough estimation of gastric emptying, it has been used frequently as an indicator of hindered gastric emptying ang motility. Because of the lack of other practical techniques it was decided to monitor RGVs at eight-our intervals to track gastric motility. During the study, early enteral nutrition was given to eight critically ill patients, whose calculated mortality risk exceeded 55\%. The applied feeding concept was found to be feasible with adverse effects rarely encountered. Splanchnic hypoperfusion - reflected by increased $\mathrm{PgaCO}_{2}$ gap, was a common finding, being detected in $70 \%$ of all measurements. These abnormalities would have remained hidden without regional perfusion monitoring, and could have contributed to the development of organ dysfunction, and worsen clinical outcome. Thirty-seven percent of patients died in the intensive care unit.

Abnormal values of arterial and central venous blood gas parameters were infrequent. Pathological values were recorded for seLac, $\mathrm{ScvO}_{2}$ and $\mathrm{PcvaCO}_{2}$ in $16 \%, 14 \%$ and $39 \%$ of all measurements, respectively. These result demonstrate the relative stability of global oxygenation and perfusion parameters compared to those of regional perfusion. The main finding is, that patients with elevated $\mathrm{PgaCO}_{2}$ had significantly higher RGVs. As the prediction of feeding intolerance is rather diffucult, the increased amount of gastric residuals in the patients with compromised tonometric parameters suggest that normalization of these parameters may positively affect the motility of the stomach. The concept of improving cardiovascular performance to reduce gastrointestinal complications in the perioperative period has already been justified in several studies [43-47]. In an examination performed in neonates decreased Doppler sonographic blood flow in the superior mesenteric artery has been linked to intestinal dysmotility and feeding intolerance [48]. These data support the assumption that perfusion of the bowel system directly affects its motility. A literature review suggests that the association between elevated mucosal $\mathrm{PCO}_{2}$ due to decreased splanchnic perfusion and the direct influence of circulatory parameters on gastric emptying and enteral feeding has not been reported.

\section{- CONCLUSION}

The use of mucosal capnometry and the measurement of mucosal-to-arterial $\mathrm{PCO}_{2}$ gap in different gastrointestinal areas proved to be useful in numerous laboratory and clinical studies. At present, the most important clinical aspect is probably the assessment of splanchnic regional blood flow in special gastrointestinal diseases. Besides compensated shock can be detected in acutely ill patients with normal macro-hemodynamic parameters, while selective gut hypoperfusion can be diagnosed in special populations with chronic gastrointestinal ischemia. In the present study, a new application field of a new gastric tonometry device was tested. The splanchnic blood flow of high-risk ICU patients receiving early enteral feeding was monitored, and significant 
differences in gastric emptying were found in patients with elevated mucosal-to-arterial $\mathrm{CO}_{2}$ gap. These data suggest that the extension of similar examinations to a greater ICU population may be worthwhile. Taking into consideration the intensive research and continuous evolution of mucosal capnometry monitoring methods, the widespread use of such devices in special medical or surgical patient groups may just be a question of time.

\section{-ACKNOWLEDGEMENTS}

The authors are very grateful for the selfless help of the nursing staff of the Department of Anaesthesiology and Intensive Therapy of the Medical University of Szeged.

\section{- CONFLICTS OF INTEREST}

The authors declare that they have no conflict of interest.

\section{- REFERENCES}

1. Pastores SM, Katz DP, Kvetan V. Splanchnic ischemia and gut mucosal injury in sepsis and the multiple organ dysfunction syndrome. Am J Gastroenterol. 1996;91:1697-710.

2. Sakr Y, Dubois MJ, De Backer D, Creteur J, Vincent JL. Persistent microcirculatory alterations are associated with organ failure and death in patients with septic shock. Crit Care Med. 2004;32:1825-31.

3. Pellis T, Weil MH, Tang W, Sun S, Csapozi P, Castillo C. Increases in both buccal and sublingual partial pressure of carbon dioxide reflect decreases of tissue blood flows in a porcine model during hemorrhagic shock. J Trauma. 2005;58:817-24.

4. Cammarata GA, Weil MH, Castillo CJ, et al. Buccal capnometry for quantitating the severity of hemorrhagic shock. Shock. 2009;31:207-11.

5. Lu H, Zheng J, Zhao P, Zhang G, Wu T. Buccal partial pressure of carbon dioxide outweighs traditional vital signs in predicting the severity of hemorrhagic shock in a rat model. J Surg Res. 2014;187:262-9.

6. Baron BJ, Sinert R, Zehtabchi S, Stavile KL, Scalea TM. Diagnostic utility of sublingual PCO2 for detecting hemorrhage in penetrating trauma patients. J Trauma. 2004;57:69-74.

7. Xu J, Ma L, Sun S, et al. Fluid resuscitation guided by sublingual partial pressure of carbon dioxide during hemorrhagic shock in a porcine model. Shock. 2013;39:361-5.

8. Palágyi P, Kaszaki J, Rostás A, et al. Monitoring microcirculatory blood flow with a new sublingual tonometer in a porcine model of hemorrhagic shock. BioMed Research International. 2015; 847152. http://dx.doi.org/10.1155/2015/847152.
9. Verdant CL, De Backer D, Bruhn A, et al. Evaluation of sublingual and gut mucosal microcirculation in sepsis: a quantitative analysis. Crit Care Med. 2009;37:2875-81.

10. Boda D, Murányi L. Gastrotonometry: an aid to the control of ventilation during arteficial respiration. Lancet. 1959;1:181-2.

11. Boda D, Tálosi G, Hódi Z. Development of gastrotonometry and the future of its use in the monitoring of critically ill patients. Orv Hetil. 2005;146:153-7.

12. Rózsavölgyi Z, Boda D, Hajnal A, Boda K, Somfay A. A Newly Developed Sublingual Tonometric Method for the Evaluation of Tissue Perfusion and Its Validation In Vitro and in Healthy Persons In Vivo and the Results of the Measurements in COPD Patients. Crit Care Res Pract. 2014;2014:534130.

13. Kolkman JJ, Mensink PB. Non-occlusive mesenteric ischaemia: a common disorder in gastroenterology and intensive care. Best Pract Res Clin Gastroenterol. 2003;17:457-73.

14. Ackland G, Grocott MP, Mythen MG. Understanding gastrointestinal perfusion in critical care: so near, and yet so far. Crit Care. 2000;4:269-81.

15. Kolkman JJ, Bargeman M, Huisman AB, Geelkerken RH. Diagnosis and management of splanchnic ischemia. World J Gastroenterol. 2008;28;14:7309-20.

16. Kolkman JJ, Otte JA, Groeneveld AB. Gastrointestinal luminal PCO2 tonometry: an update on physiology, methodology and clinical applications. Br J Anaesth. 2000;84:74-86.

17. Dubin A, Edul VS, Pozo MO, et al. Persistent villi hypoperfusion explains intramucosal acidosis in sheep endotoxemia. Crit Care Med. 2008; 36:535-42.

18. Knichwitz G, Rötker J, Möllhoff T, Richter KD, Brüssel T. Continuous intramucosal $\mathrm{PCO} 2$ measurement allows the early detection of intestinal malperfusion. Crit Care Med. 1998;26:1550-7.

19. Mensink PB, van Petersen AS, Geelkerken RH, Otte JA, Huisman $A B$, Kolkman JJ. Clinical significance of splanchnic artery stenosis. Br J Surg. 2006;93:1377-82.

20. Otte JA, Geelkerken RH, Huisman AB, Kolkman JJ. What is the best diagnostic approach for chronic gastrointestinal ischemia? Am J Gastroenterol. 2007;102:2005-10.

21. Mensink PB, van Petersen AS, Kolkman JJ, Otte JA, Huisman $A B$, Geelkerken RH. Gastric exercise tonometry: the key investigation in patients with suspected celiac artery compression syndrome. J Vasc Surg. 2006;44:277-81.

22. Kozeniecki M, Fritzshall R. Enteral nutrition for adults in the hospital setting. Nutr Clin Pract. 2015;30:634-51.

23. Braunschweig CL, Levy $P$, Sheean PM, Wang X. Enteral compared with parenteral nutrition: a meta-analysis. Am J Clin Nutr. 2001;74:534-42.

24. Gungabissoon U, Hacquoil K, Bains C, et al. Prevalence, risk factors, clinical consequences, and treatment of enteral feed intolerance during critical illness. J Parenter Enteral Nutr. 2015;39:441-8.

25. Maynard N, Bihari D, Beale R, et al. Assessment of splanchnic 
Available online at: www.jccm.ro

oxygenation by gastric tonometry in patients with acute circulatory failure. JAMA. 1993;270:1203-10.

26. Creteur J, De Backer D, Sakr Y, Vincent JL. Sublingual capnometry tracks microcirculatory changes in septic patients. Intensive Care Med. 2006;32:516-23.

27. Pernat A, Weil MH, Tang $W$, et al. Effects of hyper- and hypoventilation on gastric and sublingual PCO2. J of Appl Physiol. 1999;87:933-7.

28. Salzman AL, Strong KE, Wang H, Wollert PS, Vandermeer TJ, Fink MP. Intraluminal "balloonless" air tonometry: a new method for determination of gastrointestinal mucosal carbon dioxide tension. Crit Care Med. 1994;22:126-34.

29. Kolkman JJ, Steverink PJ, Groeneveld AB, Meuwissen SG. Characteristics of time-dependent PCO2 tonometry in the normal human stomach. Br J Anaesth. 1998;81:669-75.

30. Fiddian-Green RG, Pittenger G, Whitehouse WM Jr. Backdiffusion of $\mathrm{CO} 2$ and its influence on the intramural $\mathrm{pH}$ in gastric mucosa. J Surg Res. 1982;33:39-48.

31. Gutierrez G, Palizas F, Doglio G, et al. Gastric intramucosal $\mathrm{pH}$ as a therapeutic index of tissue oxygenation in critically ill patients. Lancet. 1992;339:195-9.

32. Heino A, Hartikainen J, Merasto ME, Alhava E, Takala J. Systemic and regional pCO2 gradients as markers of intestinal ischaemia. Intensive Care Med. 1998;24:599-604.

33. Carlesso E, Taccone P, Gattinoni L. Gastric tonometry. Minerva Anestesiol. 2006;72:529-32.

34. Bennett-Guerrero E, Panah MH, Bodian CA, et al. Automated detection of gastric luminal partial pressure of carbon dioxide during cardiovascular surgery using the Tonocap. Anesthesiology. 2000;92:38-45.

35. Creteur J, De Backer D, Sakr Y, Koch M, Vincent JL. Sublingual capnometry tracks microcirculatory changes in septic patients. Intensive Care Med. 2006;32:516-23.

36. Povoas HP, Weil MH, Tang W, Moran B, Kamohara T, Bisera J. Comparisons between sublingual and gastric tonometry during hemorrhagic shock. Chest. 2000;118:1127-32.

37. Nakagawa Y, Weil MH, Tang W, Sun S, Yamaguchi H, Jin X, Bisera
The Journal of Critical Care Medicine 2016;2(1) • 37

J. Sublingual capnometry for diagnosis and quantitation of circulatory shock. Am J Respir Crit Care Med. 1998;157:1838-43.

38. Boda D, Kaszaki J, Tálosi G. A new simple tool for tonometric determination of the $\mathrm{PCO} 2$ in the gastrointestinal tract: in vitro and in vivo validation studies. Eur J Anaesthesiol. 2006;23:680-5.

39. Chapman MJ, Deane AM. Gastrointestinal dysfunction relating to the provision of nutrition in the critically ill. Curr Opin Clin Nutr Metab Care. 2015;18:207-12.

40. Chapman MJ, Nguyen NQ, Deane AM. Gastrointestinal dysmotility: evidence and clinical management. Curr Opin Clin Nutr Metab Care. 2013;16:209-16.

41. Palágyi P, Vimláti L, Boda K, Tálosi G, Boda D. Practical experiences and in vitro and in vivo validation studies with a new gastric tonometric probe in human adult patients. J Crit Care. 2010;25:541.e9-15.

42. Joosten A, Alexander B, Cannesson M. Defining goals of resuscitation in the critically ill patient. Crit Care Clin. 2015;31:113-32.

43. Mythen MG, Webb AR. Perioperative plasma volume expansion reduces the incidence of gut mucosal hypoperfusion during cardiac surgery. Arch Surg. 1995;130:423-9.

44. Mythen MG. Postoperative gastrointestinal tract dysfunction. Anesth Analg. 2005;100:196-204.

45. Giglio MT, Marucci M, Testini M, Brienza N. Goal-directed haemodynamic therapy and gastrointestinal complications in major surgery: a meta-analysis of randomized controlled trials. Br J Anaesth. 2009;103:637-46.

46. Kirov MY, Kuzkov VV, Molnar Z. Perioperative haemodynamic therapy. Curr Opin Crit Care. 2010;16:384-92.

47. Futier $\mathrm{E}$, Robin $\mathrm{E}$, Jabaudon $\mathrm{M}$, et al. Central venous $\mathrm{O}_{2}$ saturation and venous-to-arterial $\mathrm{CO}_{2}$ difference as complementary tools for goal-directed therapy during high-risk surgery. Crit Care. 2010;14:R193.

48. Robel-Tillig E, Knüpfer M, Pulzer F, Vogtmann C. Blood flow parameters of the superior mesenteric artery as an early predictor of intestinal dysmotility in preterm infants. Pediatr Radiol. 2004;34:958-62. 